Article

\title{
Drivers for Non-Profits' Success: Volunteer Engagement and Financial Sustainability Practices through the Resource Dependence Theory
}

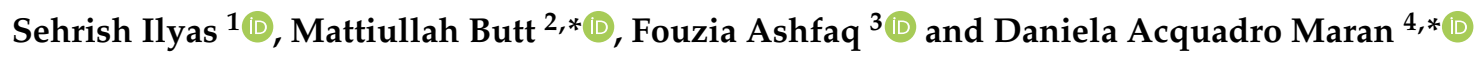 \\ 1 School of Business Administration, National College of Business Administration \& Economics (Main \\ Campus), 40 E/1 Gulberg III, Lahore 54660, Pakistan; sehrishb35@yahoo.com \\ 2 School of Business Administration, National College of Business Administration \& Economics (Front Lane \\ Campus), 168 Shadman II, Canal Road, Lahore 54610, Pakistan \\ 3 Department of Management Sciences, Lahore College for Women University, Jail Rd, Lahore 54600, Punjab, \\ Pakistan; fouziams@hotmail.com \\ 4 Department of Psychology, University of Torino, Via Verdi 10, 10124 Torino, Italy \\ * Correspondence: mmattiullah@gmail.com (M.B.); daniela.acquadro@unito.it (D.A.M.); \\ Tel.: +39-011-670-2262 (D.A.M.)
}

Received: 28 September 2020; Accepted: 13 November 2020; Published: 18 November 2020

\begin{abstract}
The strategies that non-profit organizations choose for volunteer engagement and financial sustainability are of the utmost importance for successful work. The main purpose of this study was to investigate feasible strategies for volunteer engagement and financial sustainability. Interviews were conducted to obtain data on the experience of volunteer managers in dealing with volunteers and financial matters together. Qualitative data analysis methods were used to code and analyze the data. Significant themes emerged from the data gathered through interviews that highlighted the strategies for volunteer engagement and financial sustainability chosen by the managers of non-profit organizations. From the manager's perspective, the following strategies were considered important for engaging volunteers at non-profit organizations (NPOs): 'building the skill sets of volunteers', 'fulfilling ulterior motives', and 'administering a culture of administrative support'. Moreover, 'local fundraising preference', 'transparency', and 'building trust' were regarded as successful strategies for maintaining financial sustainability. The findings of this study showed that, to function smoothly, non-profit organizations need to follow certain strategies to be cautious about volunteers as well as finance. The findings provide fruitful implications for practitioners and policy makers, and these are discussed in the paper. Furthermore, the limitations addressed in the study suggest a future direction for research in terms of study design and more focus on study informants.
\end{abstract}

Keywords: volunteer engagement retention; non-profit organizations managing volunteers; financial sustainability; managing non-profit organizations; formal volunteering; thematic analysis

\section{Introduction}

The survival of non-profit organizations (hereafter: NPOs) has been identified as an important prerequisite for measuring their success in terms of the realization of their mission (Sun et al. 2019). The determinants of non-profit success have long been a focus of the literature on strategic management. One stream of research comprehends the success and failure of NPOs as a dependent variable, whose financial (i.e., liquidity, fundraising cost, working capital etc.) and non-financial determinants (i.e., number of volunteers) can be identified through case study methods or statistical techniques (Grunert and Hildebrandt 2004; Mellahi and Wilkinson 2004). 


\subsection{Background of Study}

Due to acute competition for volunteers, the recruitment, retainment (Bussell and Forbes 2002), and management of volunteers (Carvalho and Sampaio 2017) is becoming a key concern for volunteer managers. In order to attain the strategic goals of their organizations, the leaders and executive directors of NPOs need to engage their volunteers to attain meaningful outcomes that also align with volunteers' motivations and needs (Rehnborg et al. 2005). Although NPOs do not aim for profit maximization, but for the smooth function and provision of facilities and benefits to society at large, funds are of paramount importance (Choudhury et al. 2014). Due to competition for sources of public funding, NPOs are challenged to devise workable strategies for fundraising such as the development of professionalization as well as the forming of strategic alliances through business/non-profit partnerships (Sanzo-Pérez et al. 2017). There is also a lack of known strategies for diversification that NGO executives and finance managers may practise to generate revenue (Gunnerson 2019). Furthermore, the seeking of fundraising from volunteers is prone to a spillover cost that may result in a reduction of their time with NPOs (Yeomans and Al-Ubaydli 2018), thus hampering the spirit of volunteerism.

\subsection{Novelty of the Study: Theoretical Contribution}

Although there is extant literature from the members' perspective on the engagement of employees (Saks 2006; Rao 2017) and volunteers (Manuel et al. 2011; Vecina et al. 2012), as well as the antecedents (Oostlander et al. 2014; Hyde et al. 2016) and consequences of volunteer engagement on intention to stay and retainment (Cuskelly et al. 2006; Hyde et al. 2016), there are few studies exploring the practices of volunteer resource management (Intindola et al. 2016). We intend in this study to fill this gap by enlisting formal strategies for volunteer engagement combined with practices for financial sustainability that the leaders of successful NPOs have chosen to make their NPOs growth-oriented, thus unfolding the gems of success for NPOs. However, there is sparse literature from a management perspective that explores the underlying efforts of NPO managers to enhance the engagement of their volunteers (Intindola et al. 2016), and this issue can be observed until now.

\subsection{Purpose of Study}

In light of the challenges faced by non-profits and communities, we also intend in this study to explore the avenues employed by NPO managers to maintain financial sustainability. This study will indeed contribute to third-sector literature on third-world countries. To the best of our knowledge, few studies have been conducted on the strategies for volunteer engagement and practices for financial sustainability chosen by the leaders of NPOs operating in local settings, specifically in South Asia. There are a number of studies on volunteering in America, Australia, and Europe (Kim and Kim 2015). However, most Asian countries have rich traditions of philanthropy (Lyons and Hasan 2002), demonstrating that research is still needed, especially on third-world countries. South Asia is described as the 'NGO capital of the world' because of the favourable political and social conditions for the civil society sector (Singh 2018).

Some researchers thus hold the opinion that the success of NPOs should be measured by the efficacy and efficiency of fulfilling the needs of varying stakeholders (Sales 2013) as part of their mission. In contrast, the dissolution of NPOs and their loss of control over mission accomplishment lead them towards failure (Helmig et al. 2014). Hence, in order to assess how NPOs accomplish their missions successfully, we focus in this study on identifying the strategies that volunteer managers choose to engage their volunteers and develop sound, sustainable financial plans. To achieve this objective, we chose for this research an inductive approach, through which a researcher derives a concept and theme after detailed readings of raw data (Thomas 2006). 


\section{Literature Review}

\subsection{Understanding Volunteerism with Resource Dependence Theory}

According to the Resource Dependence Theory (hereafter: RDT), organizations are dependent on multidimensional resources for their survival. Therefore, non-profit organizations not only face external pressures, but also internal pressures from management that affect their resource acquisition (Pfeffer and Salancik 2003). RDT posits that the diverse functions of organisations are influenced by their dependence on vital resources. This dependence in turn brings uncertainty, thus hampering the efficiency and effectiveness of an organization (Hillman et al. 2009). In order to operate effectively, NPOs rely on volunteers besides regular staff (Wisner et al. 2005) and limited resources to deliver sustainable service to the community (Kang 2016). Volunteers work for NPOs and welfare organizations without any need of personal gain, such as remuneration, in exchange for their services (Millette and Gagné 2008). Volunteerism is said to prosper when it enhances the overall satisfaction of motives and well-being of volunteers (Lewig et al. 2007). Thus, regardless of their time, volunteers join the cause of an NPO without requiring any monetary gain; they have varying motives behind their volunteering behaviours (Clary et al. 1998).

\subsection{Role of Volunteers and Donors in Sustainable NPOs}

According to RDT (Pfeffer and Salancik 2003), organizations operate under a constrained environment, and in order to survive and operate effectively, they tend to reduce uncertainty by managing their environments. Considering this theory from the perspective of NPOs, it is obvious that these organizations work with limited resources. The social cause and mission exhibit the demand side of an NPO, whereas volunteer engagement and financial sustainability demonstrate the supply side. Fulfilling the demand side - that is, accomplishing the mission-fosters the success of an NPO. In order to fulfil the demands on an NPO and declare it successful, a continuous stream of supply is needed. Sustained volunteering as well as a continuous stream of donations fulfil the supply side of an NPO, enriching it with an uninterrupted stream of funds and devoted individuals working with free will to attain the social cause. Thus, enhanced volunteer engagement and pertinent financial soundness will facilitate the continuity of an NPO and the accomplishment of their mission. In this way, volunteer engagement and financial sustainability become the drivers of a non-profit's success. Thus, with a continuous stream of funds and engaged volunteers, an NPO is able to foster sound planning that leads to success in terms of impact, activity, and capacity (Sawhill and Williamson 2001).

\subsection{Financial Sustainability and NPO Success}

Financial soundness is of the ultimate importance to ensuring the sustainability of NPOs (MacMillan et al. 2005), which is said to be financial sustainability. Competition for donations mitigates the sustainability of NPOs (Lyons 2003). NPOs and charitable welfare organizations look for additional revenue through alternate means, thus highlighting the importance of financial sustainability (Doherty and Murray 2007). Moreover, it has also been contended that NPOs earn a majority of their revenue from donations and public support and through their operations. NPOs are prohibited by laws regulating non-profit corporations from distributing income to managers or shareholders, termed as non-distribution constraint (Hansmann 1980). However, NPOs are mission-driven rather than profit-driven (Helmig et al. 2014) and said to exist predominantly for achieving their cause in a sustained manner; they need funds to fulfil their social causes. It is therefore a challenge for NPOs to operate within financial constraints and to manage and engage volunteers. The success of NPOs is measured in terms of mission accomplishment (Sawhill and Williamson 2001), although this is difficult to measure (Herman and Renz 1997). Sawhill and Williamson (2001) highlighted that while focusing on the success factors of NPOs, the focus should be towards the extent of mission accomplishment, not on the short-term, wrong proxies that are based primarily on financial measures (Helmig et al. 2014) due to their ease of access. Such financial indicators, when taken as the basis for measuring the 
success of NPOs, often provide misleading data on the strategic and long-term performance of NPOs (Sawhill and Williamson 2001). In addition, if NPOs fail to achieve their missions, this failure may be considered success because their mere existence represents the consistent demand for NPOs in the community (Seibel 1996). Moreover, mere dissolution does not mean failure because NPOs often cease operations when they accomplish their missions, and their members lose commitment due to the lack of a new mission, thus indicating success (Duckles et al. 2005).

\section{Methodology}

In the current study, we adopted a qualitative approach to collect data from experienced volunteer managers dealing with both volunteers and donors. A total of 17 participants completed the in-depth interviews. We selected the participants in the sample because they could provide practical insight into their managerial skills for enhancing the engagement of volunteers as well as attaining financial soundness. We collected the data in respondents' offices after receiving their consent via telephone. The study was approved by the university ethics committee, and a letter of recommendation was issued to confirm the authenticity of this study and to facilitate data collection. Respondents were assured of the anonymity of their responses through fulfilment of ethical guidelines for conducting interviews. Participation in the survey was voluntary, and participants did not receive any reward for their participation. The research conforms to the provisions of the Declaration of Helsinki (WMA 2000), and all ethical guidelines were followed as required for conducting human research, including adherence to the legal requirements of the study country.

\subsection{Context Setting for the Current Study}

The study was carried out in Pakistan, which is a developing country and the second largest economy in South Asia. NGOs play a part in the development of the economy. According to a report by the Pakistan Centre of Philanthropy (2019), the total volume of corporate donations was $1.03 \%$ $(12.77 / 12,343.5)$ of the gross domestic product (GDP) in 2018. This was apart from the numerous donations given privately to NGOs by the public. According to a report on the World Giving Index by the Charities Aid Foundation (2018), Pakistan ranks eighth in the number of people who have donated money (34 million). There are also other developing countries in the list where the public gives very large donations. NGOs supporting the poor in developing countries need to learn how donations help them to resolve their financial issues and survive. Over the last ten years, although Pakistan has ranked 41 st in donations, with $32 \%$ of the population donating, it has ranked 93rd in volunteerism, with only $13 \%$ of participants volunteering. In countries with high unemployment rates and a public that has a mind-set to give donations, NGOs need to play their part in effectively engaging people as volunteers.

\subsection{Participants}

To conduct interviews with experienced volunteer managers, we selected a two-stage sampling technique. In the first stage, from the sampling frame of registered NPOs, we drew a sample of the NPOs that fulfil our criteria as outlined in the study. This was a preliminary exercise before delving into the field. In this way, we selected only the NPOs that have operated for more than 15 years. We tried to take the number of organizations in an area based on the area's percentage of total listed NPOs (961). In the second step, we contacted experienced volunteer managers from the selected NPOs. Participant selection therefore follows a two-stage sampling procedure as outlined below:

\subsubsection{First Stage: Selecting Sample NPOs}

The NPOs included in the current study fulfilled the following criteria: (1) NPOs must have more than 15 years of operation as it is evident that older organizations are able to attract more support and donations (Arnold and Tapp 2001). (2) As geographical location has an effect on increased social network (Mano 2010), NPOs selected for this study were operating in Pakistan in order to get representative data. (3) NPOs must have volunteers in their workforces besides regular paid 
workers so that we could gain insight into the strategies chosen by managers to engage their volunteers. According to Roza et al. (2017), there a total of 3184 registered NPOs in Pakistan. However, we have included 13-or $0.4 \%$ of the total-to achieve variations in scope and activity. As some NPOs are involved in diversified activities, they sometimes covered more than one area (see Table 1). Hence, the 13 selected NPOs covered seven areas: Five provided healthcare services; two provided microfinance; seven managed primary and secondary education; two were involved in human and civil rights; three facilitated community-oriented projects; and one worked in disaster risk management (along with Micro-finance) and water, sanitation, and hygiene (along with community development). The details of the selected NPOs, including their primary areas and sub-areas of specialisation, are described in Table 1.

Table 1. Selected non-profit organizations (NPOs), areas of specialisation, and number of interviews conducted.

\begin{tabular}{|c|c|c|c|c|}
\hline ID Number & NPO & $\begin{array}{l}\text { Interviews } \\
\text { Conducted }\end{array}$ & Primary Area & Sub-Area \\
\hline 1 & Akhuwat & 3 & \multirow{2}{*}{$\begin{array}{c}\text { Micro-Finance } \\
\text { (Poverty Alleviation) }\end{array}$} & $\begin{array}{l}\text { Disaster Risk } \\
\text { Management }\end{array}$ \\
\hline 2 & Kashaf Foundation & 1 & & $\begin{array}{c}\text { Education } \\
\text { Human and Civil } \\
\text { Rights }\end{array}$ \\
\hline 3 & $\begin{array}{l}\text { Care Foundation } \\
\text { School }\end{array}$ & 1 & \multirow{4}{*}{ Education } & \\
\hline 4 & TAC school & 1 & & \\
\hline 5 & Ferozsons Trust & 1 & & Health \\
\hline 6 & Door of Awareness & 1 & & $\begin{array}{c}\text { Human and Civil } \\
\text { Rights }\end{array}$ \\
\hline 7 & $\begin{array}{l}\text { Zararshaheed } \\
\text { Welfare Trust }\end{array}$ & 1 & \multirow{4}{*}{ Health } & \\
\hline 8 & $\begin{array}{c}\text { Sundus } \\
\text { Foundation }\end{array}$ & 1 & & \\
\hline 9 & Pink Ribbon & 1 & & \\
\hline 10 & $\begin{array}{c}\text { Fatima Memorial } \\
\text { Hospital }\end{array}$ & 2 & & \\
\hline 11 & Rotary Club & 2 & \multirow{3}{*}{$\begin{array}{l}\text { Community } \\
\text { Development }\end{array}$} & \\
\hline 12 & Help in Need & 1 & & $\begin{array}{l}\text { Education } \\
\text { WASH }\end{array}$ \\
\hline 13 & Saylani & 1 & & Education \\
\hline
\end{tabular}

\subsubsection{Second Stage: Selecting Experienced Volunteer Managers}

After selecting NPOs from sample sectors, we contacted volunteer managers at the NPOs. Because our aim was to investigate strategies for enhancing the engagement of volunteers and attaining financial soundness, and thus success over time, the criterion for selecting participants was the role of the senior managers. These managers were responsible for directing, planning, monitoring the team's work, and, when necessary, suggesting corrective actions; overall, they were responsible for 'managing the systems required to link and control the company's parts' (Bartlett and Ghoshal 1995, p. 133). We conducted a total of 17 in-depth interviews. To diversify our results and obtain better understanding, we conducted sector-wise interviews-that is, from each sector, we held 2-3 interviews. Among the participants, seven (41\%) were female aged 41.86 years on average (range: $26-59)$, with an average 
work experience of 18.43 years (range: 4-34 years); 10 (59\%) were male with an average age of 44.5 (range: 35-68 years) and an average work experience of 20.3 years (range: $12-46$ years).

\subsubsection{Interviews and Time Horizon of Interviews}

We used an interview guide consisting of open-ended questions as a tracking tool to keep the interviews on track (Denzin and Lincoln 2012). To ensure reliability across interviews, we designed a guideline that included all topics of concern, followed by an introductory and background overview of the research. Interview questions addressed the topics of NPO success to provide a focused start, followed by volunteer engagement and strategies for financial sustainability. In order to reduce social desirability bias, questions relating to NPO success were phrased in a way that would extract measurable outcomes in terms of impact, activity, and capacity (Sawhill and Williamson 2001) rather than financial proxies for success such as fundraising ROI or donor growth. We also presented face-saving alternatives to participants in order to reduce social desirability bias (Neuman 2019). The interview questions were developed in view of the study's purpose, focusing on how managers engage volunteers by working with them and how they develop sound financial plans for their NPOs. Due to time constraints, the time horizon for interviews was cross-sectional and, as per Saunders et al. (2007), was limited to specific time frame. The interviews took approximately $30 \mathrm{~min}$.

\subsection{Procedure}

In order to perform thematic analysis, we first recorded all interviews and then transcribed them verbatim; in order to ensure reliability, two authors analyzed the data. Moreover, we utilized an inductive approach (Thomas 2006) to analyze the qualitative data. We gave transcripts repeated readings to familiarize ourselves with the data content. Once transcription was completed, the next stage was to code the data through the qualitative data analysis software NVIVO v. 12.0. We applied the coding by identifying the keywords employed to organize and categorize the text (Sarantakos 2012). During the coding process, the data were organized and categorized into themes and sub-themes. The emerging themes were titled with specific codes. Later, data were screened for identification of themes and categorization of NPO success factors in terms of managerial practices for engaging volunteers and achieving financial soundness. The final step included the verification of data by rechecking the transcribed data and codes.

\section{Results}

Findings are presented in two major sections—strategies for volunteer engagement and practices for financial sustainability-with eight strategies for volunteer engagement and four strategies for financial sustainability emerging from the interviews during data analysis (see Table 2).

Table 2. Volunteer engagement and financial sustainability strategies chosen by successful NPOs.

\begin{tabular}{cc}
\hline Volunteer Engagement Strategies & Financial Sustainability Practices \\
\hline Increased interaction & Local and self-funded donation \\
Fulfilling ulterior motives & Information disclosure \\
Flexibility & Building trust \\
Establishing fellowship & Diversification \\
Building personality traits and skill sets & \\
Age-differential context & \\
Emotional support & \\
Leader charisma & \\
\hline
\end{tabular}




\subsection{Volunteer Engagement Strategies}

Participants in this research were experienced volunteer managers, and they held the view that engaging volunteers was a challenge for them. They chose a variety of strategies to engage volunteers, not only physically, but also psychologically.

Increased interaction. Two respondents indicated that in order to engage their volunteers, they interacted with them on a regular basis. Moreover, our findings revealed that helping beneficiaries in an interactive way convinces them to pay back and serve society, which results in a later enhancement of their engagement. Helping in interactive ways consisted of teamwork, which builds cooperative working bonds between volunteers and NPOs. A supportive and interactive culture enhances the dedication of volunteers to sustain their involvement, which is deemed to be a proxy for volunteer engagement (Alfes et al. 2016).

'Borrowers become donors in later stages of interaction with our NPO. Borrowers put their nominal savings in the donor boxes'. (NPO1)

'We assign supervision to volunteers. We always used to have feedback to projects on a regular basis so that we could incorporate the desired changes afterwards. This is how we let our volunteers become engaged and committed'. (NPO3)

Fulfilling ulterior motives. More than four respondents believed that in order to engage volunteers, NPOs should strive to screen them for the ulterior motive of serving society. Ulterior motives are said to be the reason for one's behavior. Literature also supports the premise that in order to have engagement in the workplace, individuals need to have connection between internal motives and the external roles they are performing; disconnection between these two leads to disengagement in the workers (Kahn 1990). Behaviors are thus guided by individuals' internal motives, through which volunteers channel their efforts toward noticeable societal change; in turn, these volunteers exhibit greater emotional attachment to NPOs (Clary et al. 1998). It has also been suggested in the literature that fulfilment of career motives among volunteers encourages repeated participation (Grant 2012), which in nominal terms entails engagement with their NPOs. Two NPO managers agreed with this premise:

‘We offer people who have motives to serve society. Besides, people who come to our NPO also want to really change the system of education. Our NPO adopted a school that has only seven children. Now it has more than 100 children'. (NPO2)

Due to this alignment of personal goals with the NPO's goals, volunteers tend to engage highly and to dedicate themselves for a longer period of time:

'There are a lot of volunteers who work with us throughout the year because of their passion and interest'. (NPO1)

Flexibility. Three respondents perceived that providing flexibility to volunteers increased their tendency toward engagement. Successful NPOs are working to achieve their cause through flexible time and dedication from volunteers according to their time plan and via employer-supported volunteering (Booth et al. 2009), as illustrated by 10 NPOs:

'The mechanism varies from volunteer to volunteer. Those who are interested in fundraising are given proper receipt books to generate funds, those who want to collect clothes will be given our NPO labelled baskets'. (NPO1)

Providing creative environments and flexible roles for volunteers does positively affect volunteers' work behavior and influences their attraction to work and their retention (Barnes and Sharpe 2009). Thus, volunteers opted for a plug-in style of volunteering identified by sociologists (Lichterman and Eliasoph 2014) as having a short-term nature whereby volunteers are not bound to stay on site for long 
periods of time. Hustinx and Lammertyn (2003) also refer to this as a reflexive style of volunteering in which-instead of embedding volunteers in organizational routines-volunteers' work is more episodic. With a flexible environment, volunteers have greater engagement levels, as indicated by one respondent:

'We provide them the full ground to use their capacities .... In this way they get mentally, spiritually and physically attached with us'. (NPO4)

Our findings are supported because granting flexibility to volunteers has more astounding benefits compared to dealing with volunteers formally.

Establishing fellowship. Three respondents indicated that fellowship relationship with volunteers, increased engagement, and devotion of volunteers to the NPO they are working with. This aspect also supports previous studies showing that psychological bonds with other members makes volunteers feel highly engaged (Millette and Gagné 2008; Alfes et al. 2016). Engaging volunteers through a fellowship program by letting volunteers get closer to each other thus creates an environment of association and emotional attachment within volunteers (Doherty and Murray 2007). Emotional bonds with organizational members enabled greater attachment with the NPO and influenced volunteers' engagement (Gratton and Ghoshal 2003). Thus, employer-supported volunteering (Booth et al. 2009) also enabled NPOs to establish fellowship among their volunteers. Our findings also promote this notion:

'The second major function of our NPO is fellowship that brings together volunteers through sharing common passion... Members (volunteers) tend to combine their businesses'. (NPO7)

'We invite them for core committee meetings, occasionally on a cup of tea and have a useful exchange of ideas for the betterment of our projects. In this way they get become more committed with us'. (NPO4)

Our findings thus demonstrate that a plug-in and reflexive style of volunteering is promoted, but to engage volunteers without affecting their flexibility, their emotional attachment with the NPOs is built through fellowship and informal relationships with volunteers.

Building personality traits and skill sets. One strategy mentioned by two NPO managers about engaging their volunteers is continuously working on their personality traits and leadership skills, which provides them with a sense of accomplishment. The personality traits tend to enhance the civic engagement of volunteers (Erez et al. 2008). This occurs because the development of personal traits can motivate volunteers as an intrinsic reward. By improving their well-being, volunteers are more emotionally involved with the NPO, which also triggers their engagement. Our findings also suggest that volunteers tend to engage and stay with NPOs upon developing leadership skills:

'Our NPO's major function is to develop leadership qualities.... In this way, the personality of volunteers is developed in our NPO at national- and international-level conferences'. (NPO7)

'We provide an enabling environment to volunteers; they are taught first then given tasks, and then we monitor their performance because when they actually go in to field after in a particular sector, they must have on hand skill sets required by the organizations like report writing, monitoring, etc.'. (NPO1)

Considering age-differential contexts of volunteers. As mentioned by six respondents, one key strategy for NPOs is considering the age-differential context of volunteers (i.e., managing volunteers according to age group) because volunteers from different age groups tend to have different types of dedication and goals. The literature supports the premise that volunteerism varies across various age groups (Li and Ferraro 2006). Voluntary participation in a social cause increases in late middle 
age due to reduced family responsibilities (Curtis et al. 2001). Older volunteers have free time, but volunteerism tends to diminish with old age due to poor health ( $\mathrm{Li}$ and Ferraro 2006). Varying health benefits relate to younger and late middle-aged volunteers. The respective response is as follows:

'For young volunteerism, the satisfaction mechanism would be showing off high ends. This world benefits. For adults above the age of 30, volunteerism occurs for two reasons: this world and after this world'. (NPO7)

'We prefer to invest on fresh graduates (belonging to young age group) as they are more energetic and want to learn more than others'. (NPO1)

However, some common traits are required of volunteers irrespective of their age group, as indicated by one respondent:

'In volunteer work, you need to be rough and tough whether you are young or mature. In order to do volunteer work, you have to subordinate your own level and interest to the community level. Upon opting for such behaviour, volunteers get respect from the community, and this in turn acts as the motive for further volunteerism'. (NPO7)

Emotional support. According to two respondents, the community support and attitude fuel volunteers' energy and positive feeling about their role. Literature also concurred that, as a consequence of emotion-oriented support, volunteers tend to derive feelings of pride (Alfes et al. 2016). Positive words from the community serves as one factor for volunteer engagement with the NPO.

'The behavior of community, recognition for doing something good, and the due weight given by community tend to uplift volunteerism'. (NPO7)

'When these volunteers go to school and do something for children, the smiles on the faces of children enhance the energy for them'. (NPO2)

The emotional support provided by a community is communicated to volunteers by NPOs either through employer-supported volunteering (Booth et al. 2009) or by providing a platform for having increased interaction with the community.

Leader charisma. As mentioned by some respondents, the prevalent core value and philosophy of the NPO's members and the leader's charismatic personality both enhance the engagement of volunteers and paid workers. Leaders and managers bring charisma that sustainably beautifies the essence of volunteerism in non-profits (Bono and Ilies 2006). The response is as follows:

'Our leader has passion, so even employees are voluntarily performing. They don't want to leave this $\mathrm{NPO}^{\prime}$. (NPO1)

'There are around 7000 employees in our NPO, and the founder meet some employees in personal meetings and some through Skype sessions. His meetings spellbind employees, and they feel emotionally attached with the NPO'. (NPO1)

\subsection{Financial Sustainability Strategies}

Local and self-funded donation. Eight respondents prefer local donations from nearby industries, and members usually fund the projects with their own funding. NPOs do not prefer international funding due to constraints related to internal and external audits (Torres and Pina 2003), according to the following respondents:

'If we want international support, then it is subject to internal and external audits. Our NPO doesn't go for international funds'. (NPO2) 
'Our international club returns four times the money to us to work on the project. But, for this, an internal and external audit is mandatory'. (NPO7)

One respondent indicated that international funding is short-term and mostly project-based-once the international project is disbanded, the funding stops. Thus, expanded NPO operations based on international funding are subject to closure in future:

'We don't prefer donation from international agencies because these agencies are project based. So, we don't want to expand on their funds and then later due to lack of fund flow, we have to close our schools'. (NPO2)

Due to these constraints, NPOs prefer local and self-funded donations for sustained operations:

'So, in order to provide sustained services to a community, our foundation goes for local donors and nearby industries. They would have an interest in visiting the school and fulfilling their motive to do something for their community. In this way, the quality of education is enhanced and this process will remain ongoing'. (NPO2)

'Our policy is that we have to maintain the $20-25 \%$ liquidity of our total balance sheet. If there are any delays in raising funds or if any loan approval issues are on the way, so we must have enough funds that we can survive 3-4 months easily without any fund raising'. (NPO3)

'We basically execute local fund-raising programs and focus more on zakat being given by the people'. (NPO12)

Information disclosure. Four respondents believe that information disclosure is one of the key elements of their financial sustainability. Information disclosure is an important prerequisite for accountability of NPOs (Zainon et al. 2014). The stakeholders of NPOs (i.e., creditors, investors, clients, and donors) gauge the performance of NPOs through annual reports (Keating and Frumkin 2003). NPOs' annual reports are deemed the primary source of communication with key stakeholders regarding their activities (Hyndman and Anderson 1995). Respondents perceive that providing financial disclosure to stakeholders via financial statements helps sustain long-term healthy relationships with donors:

'We provide quarterly reports to our donors for their respective schools to which they have donated a sum. These reports sum up the three months in a pre-post comparative report on a number of enrolments, board results, what sort of projects are running, the number of students who participated in these projects, and a record of their prizes'. (NPO2)

NPOs largely share their audited information in the context of their donation:

'In order to provide information to our stakeholders, we disclose our financial results of the year in the form of financial statements that are fair and free from any misstatements'. (NPO1)

Respondents also believe that information disclosure has been the fundamental source of reliability and accountability for financial providers. Over five respondents believe this aspect enhances donors' confidence in NPOs and ensures sustainable financial streams for NPOs:

'Besides, we assure that our annual reports fully disclose the nature of our activities'. (NPO6)

"In this way, our donors feel confident that their money is in safe hands and will reach the needy. Thus, they continue their funding with us'. (NPO12) 
Building trust. Over six participants indicated that financial soundness occurs via long-term relationships with donors, which is made possible by establishing a relationship of trust. Trust in NPOs is one key factor of continued donations (Sargeant and Lee 2004). Our findings support the literature in that NPOs must build trust with donors via strong emotional bonds and transparency in all aspects (through annual reports) to have sustained donations from donors. Such reports provide information about the dispersion of funds, which builds trust among donors:

'We try to achieve the goals and mission of our NPO, so people have trust in us ... and we sustain that funding by trusting the people to last many years'. (NPO8)

'We have been successful in achieving our mission, so this aspect supports the notion that our success has been backed by our donors, too. So, we have been strong not only in achieving our mission but also financially. So, since last five years, donors have established trust in our foundation as compared to other NPOs of same cause. One of the foremost reasons is our work and, secondly, our board of trustees—who don't take even a single cent for salary'. (NPO6)

'We ensure the sustainability of local funding through the trust we developed with respect to our communication with them'. (NPO9)

Two donors also indicated that NPOs showing gratitude and respect toward donors also inspired donors to continue donating, hence establishing financial sustainability:

'To generate more funds, we are sending 'Thank You' letters to donors to make them part of this system being created and to influence other prospective donors. This helps in attaining long-term relationship with our donors'. (NPO13)

'We do try our level best to be in contact with all these local donors by organizing various functions; we used to invite them all in a very respectful manner. In this way, these donors provide us with continued donations'. (NPO3)

Diversification. Regarding the sustainability of funds, five respondents demonstrated that, being a non-profit organization, their focus is to diversify their basket of funds. NPOs normally do not depend on one source of fund due to scarce resources rather work on diversified funding strategies to survive in face of resource dependence realm (Froelich 1999).

'We use different tools for fundraising because if we choose only one tool for fundraising then it would be questionable for the sustained performance of the NPO. So, for this, we target national donors comprising an individual sector, a corporate sector, and schools and colleges for generating funds. Besides, we have donation boxes for fundraising. In schools and colleges, we have campaigned by ticket selling for fundraising'. (NPO6)

'There are two or three funds that are available to us for this organization, and some annually fixed funds are provided by the government of Punjab. Other funds are generated through donations made by different anonymous people'. (NPO13)

'We basically execute local fund-raising programs and focus more on zakat given by the people. We also use the profits generated from the treatment of private patients'. (NPO12)

In addition, four respondents described their various sources of fundraising as follows:

'Through seminars and awareness campaigns in member's institutions, we motivate people to come and join us through the newspaper, media, TV talk shows, and websites'. (NPO7)

'There are two or three funds that are available to us for this organization, and some annually fixed funds are provided by the government of Punjab. Other funds are generated through donations made anonymously by different people'. (NPO13) 


\section{Discussion}

According to RDT (Pfeffer and Salancik 2003), resources are crucial for NPOs' operations. NPOs' resources primarily comprise two forms: Financial and human. NPOs' financial resources are overwhelmingly from donations and sponsors, and their human resources comprise paid staff and volunteers. So, volunteer engagement and financial sustainability are both parallel components of a successful NPO when implemented efficiently and effectively (Sawhill and Williamson 2001). Volunteer engagement is said to be pivotal and critical to non-profit organizations (Hyde et al. 2016).

The sub-themes of volunteer engagement strategies indicated that support given to volunteers by managers and respective organizations is important for volunteer engagement. The literature also supports the notion that volunteer engagement is enhanced by increased organizational support and identification (Alfes et al. 2016; Malinen and Harju 2017). Via a quantitative data analysis, Kang (2016) found that identification and satisfaction significantly relate to volunteer engagement. Organizational support by volunteer managers and NPOs can motivate volunteers. As highlighted by study participants, such support combined with respect from the community tends to motivate them extrinsically. Besides, doing good in the community also intrinsically motivates them by fulfilling their internal motivation to do good deeds. Our findings on intrinsic and extrinsic motivation also support previous studies on the intrinsic and extrinsic motivations of volunteers (Bidee et al. 2013; Borzaga and Tortia 2006; Finkelstien 2009). Frey (1997) first introduced the concept of intrinsic incentive. Under various circumstances, intrinsic incentives (non-monetary) are crowded out by extrinsic incentives (monetary). Farmer and Fedor (2001) suggest that people volunteer their services for altruistic rather than materialistic reasons. According to Frey (1997), workers are motivated by extrinsic and intrinsic aspects of the job, in addition to relational and economic aspects. Workers are extrinsically motivated when they can attain recognition, greater training opportunities, and greater flexibility. In addition, participating in the management of an organization, contributing to society, and finding an opportunity for self-fulfillment intrinsically motivate workers. Our findings also revealed a "plug-in" and "collective and reflexive" volunteering style prevailed in Pakistan. A plug-in and reflexive style of volunteering is promoted (as mentioned in flexibility theme), but to engage volunteers without affecting their flexibility, their emotional attachment with the NPOs is built via fellowship and informal relationship with volunteers. This commitment and attachment with NPOs do not bind them to stay, but trigger volunteers to work during their free time to adopt flexibility. Thus, both themes somewhat relate to each other, where one theme (establishing fellowship) instigates the other (flexibility).

Knowing the extent of volunteer motivation, NPOs can become empowered and equipped to reap fruitful contributions from engaged volunteers, thus enabling quality service for mankind, and helping NPOs succeed in their domain. Our results are cross validated by extant literature on volunteer motivation via other quantitative methods (for example Alfes et al. 2016; Clary and Snyder 1999). In addition, by enhancing volunteers' engagement through various strategies mentioned in results section, most respondents indicated that engaged volunteers can deliver services to society in a superior and sustained manner. Volunteers' persistent volunteerism occurs due to their identification with NPOs due to the uniqueness of a social cause. Of the respondents, $87 \%$ described their NPO as a pioneer in this cause and no other NPO is operating per their agenda. A unique contribution of NPOs depends upon improving the process and on procedural innovation (Froelich 1999), in contrast to product innovation that occurs in for-profit organizations. Procedural innovation indicates new and innovative ways for NPOs to deliver services to constituencies (Clary et al. 1998). Accordingly, successful NPOs strive to deliver products and services in a unique fashion by focusing on the process. The subthemes of improving NPOs' financial sustainability revealed some unique findings about preferring persistent local funding sources over project-based and international funding. The results suggested that local NPOs operating at a small scale receive funding from nearby industries with a more long-term nature compared to international funding. The reason highlighted by most of respondents was that the industries are enthusiastic about their community's welfare and about ensuring the sustainability of 
operations. These findings contribute to the literature about the donation preferences of local NPOs in third-world countries and in emerging economies, like that of Pakistan. Firstly, to the authors' best knowledge, this study is the first to delineate the NPOs' preference for local over international donations. In this way, our findings suggest that NPOs can enhance their sustained performance by targeting local businesses and by putting donation boxes in their outlets. Findings also indicated that NPOs with an increasing registered donor base ensured their increased trust from the community, thus indicating their success. In this regard, an effectively operated NPO tends to have increased donations (Som et al. 2012). Funders and donors want NPOs to work in an accountable and transparent manner (Sanzo-Pérez et al. 2017).

\section{Managerial Implications}

This paper found fruitful implications for the leaders and managers of NPOs in enhancing their volunteers' emotional attachment, improving their empowerment and energy levels at work, and attaining sound financial plans.

Firstly, leaders can benefit from this study by incorporating measurable tools for success indicators and by devising a sound financial plan to sustain and deliver continuous services for society.

Secondly, this study provides practical implications for operating/middle managers by giving them techniques for enhancing volunteers' engagement that will eventually enable them to retain these volunteers for a longer time.

Finally, to make NPOs successful in achieving their social cause, the findings suggest the leaders of non-profit organizations should be involved in empowering volunteers and enhancing their psychological association with NPOs to retain them. Leaders should also work on a sound financial plan to deliver continuous services to society.

\section{Limitations}

The current study poses several limitations. Firstly, the study is qualitative, so the results might still be influenced by the idiosyncrasies and personal biases of the researchers. Future research might adopt a sequential mixed-method design to cross validate this study's findings by using a scale that potentially matches the study's epistemology. Secondly, the current study addressed the volunteer engagement and financial sustainability only of successful NPOs. Future studies may validate these finding by comparing the results with unsuccessful or struggling NPOs. Thirdly, this research was conducted in Pakistan by using a sample of experienced volunteer managers for NPOs operating for over 15 years. Future research could be conducted in other southern countries via different approaches (i.e., focus group) to validate the current study's findings. Moreover, the role of the managers' gender was not investigated. For example, Gudjonsson et al. (2020) found that having a significant rate of women-especially in management positions with decision-making roles - can contribute to the financial sustainability of micro-finance institutions. Wymer (2011) has discussed plenty of literature showing the significant contribution of women towards volunteering compared to males. Women volunteer more, give more time more frequently, have more motivation, and are more interested and more committed to volunteering (Mesch et al. 2006; Wymer and Samu 2002). Similarly, women donate more and more effectively manage volunteers compared to men (Wymer 2011). Being more inclined to volunteering, women's involvement in volunteer organizations' decision making may support its financial stability.

\section{Conclusions}

The current study is aimed at identifying the volunteer engagement and financial sustainability strategies of successful NPOs in a South Asian context (i.e., Pakistan). Volunteers are essential to the sustainability and growth of NPOs and communities. With engagement from highly effective volunteers, NPOs tend to prosper and thus develop a selfless and altruistic culture. The factors of volunteer engagement highlighted most by volunteer managers were a leader's charismatic role, the 
flexibility offered to volunteers, acknowledgments from celebrities, participation in decision making, personal development, transparent disclosures of donations, and effective coordination with volunteers. Furthermore, to devise a sound financial succession plan for an NPO's sustained operation, participants explained some common factors, such as the preference for local donations, information disclosure to donors, diversified sources of funds, and building trust among donors. While devising strategies for volunteer engagement and financial soundness, NPOs become stable and successfully achieved their social cause in a sustainable fashion.

Author Contributions: Conceptualization, M.B.; Methodology, M.B.; Formal Analysis, S.I.; Investigation, S.I., F.A.; Data Curation, S.I., F.A.; Writing-Original Draft Preparation, S.I.; Writing-Review \& Editing, D.A.M.; Project Administration, M.B. All authors have read and agreed to the published version of the manuscript.

Funding: This research received no external funding.

Conflicts of Interest: The authors declare no conflict of interest.

\section{References}

Alfes, Kerstin, Amanda Shantz, and Catherine Bailey. 2016. Enhancing volunteer engagement to achieve desirable outcomes: What can non-profit employers do? Voluntas: International Journal of Voluntary and Nonprofit Organizations 27: 595-617. [CrossRef]

Arnold, Mark J., and Shelley R. Tapp. 2001. The effects of direct marketing techniques on performance: An application to arts organizations. Journal of Interactive Marketing 15: 41-52. [CrossRef]

Barnes, Martha L., and Erin K. Sharpe. 2009. Looking beyond traditional volunteer management: A case study of an alternative approach to volunteer engagement in parks and recreation. Voluntas: International Journal of Voluntary and Nonprofit Organizations 20: 169. [CrossRef]

Bartlett, Christopher A., and Sumantra Ghoshal. 1995. Changing the role of top management: Beyond systems to people. Harvard Business Review 73: 132-42.

Bidee, Jemima, Tim Vantilborgh, Roland Pepermans, Gert Huybrechts, Jurgen Willems, Marc Jegers, and Joeri Hofmans. 2013. Autonomous motivation stimulates volunteers' work effort: A self-determination theory approach to volunteerism. Voluntas: International Journal of Voluntary and Nonprofit Organizations 24: 32-47. [CrossRef]

Bono, Joyce E., and Remus Ilies. 2006. Charisma, positive emotions and mood contagion. The Leadership Quarterly 17: 317-34. [CrossRef]

Booth, Jonathan E., Kyoung Won Park, and Theresa M. Glomb. 2009. Employer-supported volunteering benefits: Gift exchange among employers, employees, and volunteer organizations. Human Resource Management 48: 227-49. [CrossRef]

Borzaga, Carlo, and Ermanno Tortia. 2006. Worker motivations, job satisfaction, and loyalty in public and nonprofit social services. Nonprofit and Voluntary Sector Quarterly 35: 225-48. [CrossRef]

Bussell, Helen, and Deborah Forbes. 2002. Understanding the volunteer market: The what, where, who and why of volunteering. International Journal of Nonprofit and Voluntary Sector Marketing 7: 244-57. [CrossRef]

Carvalho, Ana, and Martinha Sampaio. 2017. Volunteer management beyond prescribed best practice: A case study of Portuguese non-profits. Personnel Review 46: 410-28. [CrossRef]

Charities Aid Foundation. 2018. CAF World Giving Index 2018: A Global View of Giving Trends. West Malling: Charities Aid Foundation.

Choudhury, Masudul Alam, Teruyo Omura, and John Forster. 2014. Competition for donations and the sustainability of not-for-profit organisations. Humanomics 30: 255-74.

Clary, E. Gil, and Mark Snyder. 1999. The motivations to volunteer: Theoretical and practical considerations. Current Directions in Psychological Science 8: 156-59. [CrossRef]

Clary, E. Gil, Mark Snyder, Robert D. Ridge, John Copeland, Arthur A. Stukas, Julie Haugen, and Peter Miene. 1998. Understanding and assessing the motivations of volunteers: A functional approach. Journal of Personality and Social Psychology 74: 1516. [CrossRef] [PubMed]

Curtis, James E., Douglas E. Baer, and Edward G. Grabb. 2001. Nations of joiners: Explaining voluntary association membership in democratic societies. American Sociological Review 66: 783-805. [CrossRef] 
Cuskelly, Graham, Tracy Taylor, Russell Hoye, and Simon Darcy. 2006. Volunteer management practices and volunteer retention: A human resource management approach. Sport Management Review 9: 141-63. [CrossRef]

Denzin, Norman K., and Yvonna S. Lincoln. 2012. Strategies of Qualitative Inquiry, 4th ed. Thousand Oaks, Inc.: SAGE Publications.

Doherty, Alison, and Martha Murray. 2007. The strategic sponsorship process in a non-profit sport organization. Sport Marketing Quarterly 16: 49.

Duckles, Beth M., Mark A. Hager, and Joseph Galaskiewicz. 2005. How nonprofits close. Qualitative Organizational Research 1: 169-203.

Erez, Ayelet, Mario Mikulincer, Marinus H. van Ijzendoorn, and Pieter M. Kroonenberg. 2008. Attachment, personality, and volunteering: Placing volunteerism in an attachment-theoretical framework. Personality and Individual Differences 44: 64-74. [CrossRef]

Farmer, Steven M., and Donald B. Fedor. 2001. Changing the focus on volunteering: An investigation of volunteers' multiple contributions to a charitable organization. Journal of Management 27: 191-211. [CrossRef]

Finkelstien, Marcia A. 2009. Intrinsic vs. extrinsic motivational orientations and the volunteer process. Personality and Individual Differences 46: 653-58. [CrossRef]

Frey, Bruno S. 1997. Not Just for the Money an Economic Theory of Personal Motivation. Cheltenham: Edward Elgar Pub.

Froelich, Karen A. 1999. Diversification of revenue strategies: Evolving resource dependence in nonprofit organizations. Nonprofit and Voluntary Sector Quarterly 28: 246-68. [CrossRef]

Grant, Adam M. 2012. Giving time, time after time: Work design and sustained employee participation in corporate volunteering. Academy of Management Review 37: 589-615. [CrossRef]

Gratton, Lynda, and Sumantra Ghoshal. 2003. Managing Personal Human Capital: New Ethos for the 'Volunteer'Employee. European Management Journal 21: 1-10. [CrossRef]

Grunert, Klaus G., and Lutz Hildebrandt. 2004. Success factors, competitive advantage and competence development. Journal of Business Research 57: 459-61. [CrossRef]

Gudjonsson, Sigurdur, Kari Kristinsson, Haukur Freyr Gylfason, and Inga Minelgaite. 2020. Female advantage? Management and financial performance in microfinance. Business: Theory and Practice 21: 83-91. [CrossRef]

Gunnerson, Alan Lee. 2019. Strategies to Diversify Funding Sources in Nonprofit Organizations. Available online: http://proxy.cc.uic.edu/login?url=https://search.proquest.com/docview/2177274673?accountid= 14552\%0Ahttp://hz9pj6fe4t.search.serialssolutions.com?ctx_ver=Z39.88-2004\&ctx_enc=info:ofi/enc: UTF-8\&rfr_id=info:sid/ProQuest+Dissertations+\%26+Theses+A\%26I\&rft_val (accessed on 28 July 2020).

Hansmann, Henry B. 1980. The role of nonprofit enterprise. The Yale Law Journal 89: 835-901. [CrossRef]

Helmig, Bernd, Stefan Ingerfurth, and Alexander Pinz. 2014. Success and failure of nonprofit organizations: Theoretical foundations, empirical evidence, and future research. Voluntas: International Journal of Voluntary and Nonprofit Organizations 2: 1509-38. [CrossRef]

Herman, Robert D., and David O. Renz. 1997. Multiple constituencies and the social construction of nonprofit organization effectiveness. Nonprofit and Voluntary Sector Quarterly 26: 185-206. [CrossRef]

Hillman, Amy J., Michael C. Withers, and Brian J. Collins. 2009. Resource dependence theory: A review. Journal of Management 35: 1404-27. [CrossRef]

Thomas, David R. 2006. A general inductive approach for analyzing qualitative evaluation data. American Journal of Evaluation 27: 237-46.

Hustinx, Lesley, and Frans Lammertyn. 2003. Collective and reflexive styles of volunteering: A sociological modernization perspective. Voluntas: International Journal of Voluntary and Nonprofit Organizations 14: 167-87. [CrossRef]

Hyde, Melissa K., Jeff Dunn, Caitlin Bax, and Suzanne K. Chambers. 2016. Episodic volunteering and retention: An integrated theoretical approach. Nonprofit and Voluntary Sector Quarterly 45: 45-63. [CrossRef]

Hyndman, Noel S., and Robert Anderson. 1995. The use of performance information in external reporting: An empirical study of UK executive agencies. Financial Accountability \& Management 11: 1-17.

Intindola, Melissa, Sean Rogers, Carol Flinchbaugh, and Doug Della Pietra. 2016. Hospital administrative characteristics and volunteer resource management practices. Journal of Health Organization and Management 30: 372-89. [CrossRef] [PubMed] 
Kahn, William A. 1990. Psychological conditions of personal engagement and disengagement at work Academy of Management Journal 33: 692-724. 33: 692-724.

Kang, Minjeong. 2016. Moderating effects of identification on volunteer engagement: An exploratory study of a faith-based charity organization. Journal of Communication Management 20: 102-17. [CrossRef]

Keating, Elizabeth K., and Peter Frumkin. 2003. Reengineering nonprofit financial accountability: Toward a more reliable foundation for regulation. Public Administration Review 63: 3-15. [CrossRef]

Kim, Seok Eun, and You Hyun Kim. 2015. Measuring the growth of the nonprofit sector: A longitudinal analysis. Public Administration Review 75: 242-51. [CrossRef]

Lewig, Kerry A., Despoina Xanthopoulou, Arnold B. Bakker, Maureen F. Dollard, and Jacques C. Metzer. 2007. Burnout and connectedness among Australian volunteers: A test of the Job Demands-Resources model. Journal of Vocational Behavior 71: 429-45. [CrossRef]

Li, Yunqing, and Kenneth F. Ferraro. 2006. Volunteering in middle and later life: Is health a benefit, barrier or both? Social Forces 85: 497-519. [CrossRef]

Lichterman, Paul, and Nina Eliasoph. 2014. Civic action. American Journal of Sociology 120: 798-863. [CrossRef]

Lyons, Mark. 2003. The legal and regulatory environment of the third sector. Asian Journal of Public Administration 25: 87-106. [CrossRef]

Lyons, Mark, and Samiul Hasan. 2002. Researching Asia's third sector. Voluntas: International Journal of Voluntary and Nonprofit Organizations 13: 107-12. [CrossRef]

MacMillan, Keith, Kevin Money, Arthur Money, and Steve Downing. 2005. Relationship marketing in the not-for-profit sector: An extension and application of the commitment-trust theory. Journal of Business Research 58: 806-18. [CrossRef]

Malinen, Sanna, and Lotta Harju. 2017. Volunteer engagement: Exploring the distinction between job and organizational engagement. Voluntas: International Journal of Voluntary and Nonprofit Organizations 28: 69-89. [CrossRef]

Mano, Rita S. 2010. Marketing and performance evaluations in non-profit services. International Journal of Productivity and Performance Management 59: 555-70. [CrossRef]

Manuel, Douglas G., Kelvin Lam, Sarah Maaten, and Julie Klein-Geltink. 2011. Using administrative data to measure the extent to which practitioners work together: "interconnected" care is common in a large cohort of family physicians. Open Medicine 5: e177. [PubMed]

Mellahi, Kamel, and Adrian Wilkinson. 2004. Organizational failure: A critique of recent research and a proposed integrative framework. International Journal of Management Reviews 5: 21-41. [CrossRef]

Mesch, Debra J., Patrick M. Rooney, Kathryn S. Steinberg, and Brian Denton. 2006. The effects of race, gender, and marital status on giving and volunteering in Indiana. Nonprofit and Voluntary Sector Quarterly 35: 565-87. [CrossRef]

Millette, Valérie, and Marylene Gagné. 2008. Designing volunteers' tasks to maximize motivation, satisfaction and performance: The impact of job characteristics on volunteer engagement. Motivation and Emotion 32: 11-22. [CrossRef]

Neuman, Lawrence W. 2019. Social Research Methods: Qualitative and Quantitative Approaches, 8th ed. Harlow Essex: Pearson Edinburgh Gate.

Oostlander, Jeannette, Stefan T. Güntert, Susan Van Schie, and Theo Wehner. 2014. Leadership and volunteer motivation: A study using self-determination theory. Nonprofit and Voluntary Sector Quarterly 43: 869-89. [CrossRef]

Pakistan Centre of Philanthropy. 2019. Corporate Philanthropy in Pakistan. Islamabad: UNDP, Available online: https://www.sdgpakistan.pk/uploads/pub/Corporate_Philanthropy_in_Pakistan_2017_Feb_2019_ FINAL.pdf (accessed on 20 July 2020).

Pfeffer, Jeffrey, and Gerald R. Salancik. 2003. The External Control of Organizations: A Resource Dependence Perspective. Stanford: Stanford University.

Rao, M.S. 2017. Innovative tools and techniques to ensure effective employee engagement. Industrial and Commercial Training 49: 127-31. [CrossRef]

Rehnborg, Sarah Jane, Wanda Lee Bailey, Meg Moore, and Christine Sinatra. 2005. Maximizing Volunteer Engagement: A Snapshot for Executive Directors. Austin: RGK Center for Philanthropy and Community Service.

Roza, Lonneke, Itamar Shachar, Lucas Meijs, and Lesley Hustinx. 2017. The nonprofit case for corporate volunteering: A multi-level perspective. The Service Industries Journal 37: 746-65. [CrossRef] 
Saks, Alan M. 2006. Antecedents and consequences of employee engagement. Journal of Managerial Psychology 21: 600-19. [CrossRef]

Sales, Xavier. 2013. Performance Management System in a Non-profit Local Governmental Broadcaster. Global Business \& Management Research 5: 13-23.

Sanzo-Pérez, María José, Marta Rey-Garcia, and Luis Ignacio Álvarez-González. 2017. The drivers of voluntary transparency in nonprofits: Professionalization and partnerships with firms as determinants. Voluntas: International Journal of Voluntary and Nonprofit Organizations 28: 1595-621. [CrossRef]

Sarantakos, Sotirios. 2012. Social Research. London: Macmillan International Higher Education.

Sargeant, Adrian, and Stephen Lee. 2004. Donor trust and relationship commitment in the UK charity sector: The impact on behavior. Nonprofit and Voluntary Sector Quarterly 33: 185-202. [CrossRef]

Saunders, M., P. Lewis, and A. Thornhill. 2007. Research methods. In Business Studentsition, 4th ed. Harlow: Pearson Education Limited.

Sawhill, John C., and David Williamson. 2001. Mission impossible?: Measuring success in nonprofit organizations. Nonprofit Management and Leadership 11: 371-86. [CrossRef]

Seibel, Wolfgang. 1996. Successful failure: An alternative view on organizational coping. American Behavioral Scientist 39: 1011-24. [CrossRef]

Singh, Gurharpal. 2018. South Asia. In Democratization through the Looking-Glass. Manchester: Manchester University Press.

Som, Hishamuddin bin Md, Roland Yeow Theng Nam, Sazali Abdul Wahab, Rashid Nordin, and A. H. Mashkuri. 2012. The implementation of learning organization elements and their impact towards organizational performance amongst NPOs in Singapore. International Journal of Business and Management 7: 2-35.

Sun, Chen-Yi, Yen-An Chen, and Xiuzhi Zhang. 2019. Key Factors in the Success of Eco-Communities in Taiwan's Countryside: The Role of Government, Partner, and Community Group. Sustainability 11: 1208. [CrossRef]

Torres, Lourdes, and Vicente Pina. 2003. Accounting for accountability and management in NPOs. A comparative study of four countries: Canada, the United Kingdom, the USA and Spain. Financial Accountability $\mathcal{E}$ Management 19: 265-85.

Vecina, María L., Fernando Chacón, Manuel Sueiro, and Ana Barrón. 2012. Volunteer engagement: Does engagement predict the degree of satisfaction among new volunteers and the commitment of those who have been active longer? Applied Psychology 61: 130-48. [CrossRef]

Wisner, Priscilla S., Anne Stringfellow, William E. Youngdahl, and Lenore Parker. 2005. The service volunteer-loyalty chain: An exploratory study of charitable not-for-profit service organizations. Journal of Operations Management 23: 143-61. [CrossRef]

World Medical Association. 2000. Declaration of Helsinki, ethical principles for medical research involving human subjects. Paper presented at 52nd WMA General Assembly, Edinburgh, UK, October 3-7.

Wymer, Walter. 2011. The implications of sex differences on volunteer preferences. Voluntas: International Journal of Voluntary and Nonprofit Organizations 22: 831-51. [CrossRef]

Wymer, Walter W., Jr., and Sridhar Samu. 2002. Volunteer service as symbolic consumption: Gender and occupational differences in volunteering. Journal of Marketing Management 18: 971-89. [CrossRef]

Yeomans, Michael, and Omar Al-Ubaydli. 2018. How does fundraising affect volunteering? Evidence from a natural field experiment. Journal of Economic Psychology 64: 57-72. [CrossRef]

Zainon, Saunah, Ruhaya Atan, and Y. Bee Wah. 2014. An empirical study on the determinants of information disclosure of Malaysian non-profit organizations. Asian Review of Accounting 22: 35-55. [CrossRef]

Publisher's Note: MDPI stays neutral with regard to jurisdictional claims in published maps and institutional affiliations.

(C) 2020 by the authors. Licensee MDPI, Basel, Switzerland. This article is an open access article distributed under the terms and conditions of the Creative Commons Attribution (CC BY) license (http://creativecommons.org/licenses/by/4.0/). 